\title{
Hematologic Emergencies in the PICU
}

\author{
Martin C.J. Kneyber
}

\begin{abstract}
The pediatric critical care physician is frequently challenged by hematologic abnormalities in critically ill children admitted to the pediatric intensive care unit (PICU). The challenge is to differentiate between primary hematologic emergencies that require critical care interventions and abnormalities secondary to other disease conditions. It is therefore necessary for the pediatric critical care physician to collaborate with the pediatric hematologist when managing such patients. This chapter summarizes some of the most common hematologic emergencies of red blood cell (RBC), white blood cell (WBC), or platelet disorders observed in critically ill children that may require attention of the pediatric critical care physician.
\end{abstract}

Keywords

Hematologic emergency $\bullet$ Erythrocyte $\bullet$ Platelets $\bullet$ Sickle cell disease $\bullet$ White blood cells

\section{Introduction}

The pediatric critical care physician is frequently challenged by hematologic abnormalities in critically ill children admitted to the pediatric intensive care unit (PICU). The challenge is to differentiate between primary hematologic emergencies that require specific interventions and abnormalities secondary to other disease conditions. The purpose of this chapter is to summarize some of the most common hematologic emergencies seen in critically ill children that are associated with red blood cell (RBC), white blood cell (WBC) or platelet disorders. Transfusion medicine, oncologic emergencies, and coagulation disorders are discussed in other chapters. Of importance, many patients admitted for other reasons may have underlying disorders of elements of blood. It is beyond

M.C.J. Kneyber, $\mathrm{MD}, \mathrm{PhD}$

Division of Paediatric Intensive Care, Department of Paediatrics, Beatrix Children's Hospital, University Medical Centre Groningen, The University of Groningen,

30.001, Groningen, The Netherlands 9700RB

e-mail: m.c.j.kneyber@umcg.nl the scope of this chapter to go into detail about many of these disorders. The reader is kindly referred to books on pediatric hematology. As a consequence, it is therefore necessary for the pediatric critical care physician to collaborate with the pediatric hematologist when managing such patients.

\section{Part 1: Red Blood Cell Disorders}

Anemia is common in critically ill children. In a prospective multicenter observational study performed in 30 NorthAmerican PICUs it was observed that $33 \%$ of the patients had anemia (defined by the Hb concentration two standard deviations below the mean normal $\mathrm{Hb}$ concentration for each group) upon PICU admission and $18 \%$ developed anemia $>48 \mathrm{~h}$ after PICU admission [1]. Acute anemia is mainly due to acute blood loss, aggressive fluid resuscitation with crystalloids, acute hemolysis, or acute splenic sequestration. Subacute anemia in critically ill children is frequently caused by repetitive daily blood sampling usually done in the PICU [2].

A large number of diseases will lead to some form of anemia (Table 20.1). In general these causes can be 
Table 20.1 Classification of anemia

\begin{tabular}{|c|c|}
\hline \multirow[t]{11}{*}{ Decreased production } & $\begin{array}{l}\text { Impaired development of red blood } \\
\text { cells }\end{array}$ \\
\hline & Aplastic anemia \\
\hline & Bone marrow infiltration \\
\hline & Bone marrow hypoplasia \\
\hline & Pure red cell aplasia \\
\hline & $\begin{array}{l}\text { Transient erythrocytopenia } \\
\text { of childhood }\end{array}$ \\
\hline & $\begin{array}{l}\text { Inadequate production of } \\
\text { erythropoietin }\end{array}$ \\
\hline & Chronic disease \\
\hline & Endocrine disorders \\
\hline & Malnutrition \\
\hline & Renal disorders \\
\hline \multirow[t]{5}{*}{ Maturation impairment } & Iron deficiency \\
\hline & Lead poisoning \\
\hline & Sideroblastic anemia \\
\hline & Thalassemias \\
\hline & Vitamine B12 or folate deficiency \\
\hline \multirow{9}{*}{$\begin{array}{l}\text { Increased destruction or } \\
\text { turn-over }\end{array}$} & (Auto-) Immune-mediated \\
\hline & Drug-induced \\
\hline & Dyshemoglobinemias \\
\hline & Enzymopathy \\
\hline & $\begin{array}{l}\text { Hemoglobinopathies (sickle cell } \\
\text { disease) }\end{array}$ \\
\hline & Infection-related \\
\hline & Spherocytosis \\
\hline & Burns \\
\hline & Hemophagocytic syndrome \\
\hline
\end{tabular}

classified as resulting from underproduction, impaired maturation, or increased turn-over or destruction (i.e. hemolysis) of RBCs. Hemolysis can be attributed to numerous causes originating from either intracellular or extracellular disorders, including RBC membrane defects, abnormal erythrocyte metabolism, immune mediated hemolysis (for instance $\mathrm{ABO}$ mismatch or auto-immune mediated hemolysis), and primary hemoglobinopathies such as thalassemias and sickle cell disease (SCD). Diseases leading to anemia can be identified by symptoms and diagnostic investigations (Table 20.2), of which the cell indices provide important information, in particular the mean corpuscular volume (MCV) (Table 20.3) [3].

Irrespective of its cause, anemia results in decreased $\mathrm{O}_{2}$ carrying capacity and ultimately decreased $\mathrm{O}_{2}$ delivery $\left(\mathrm{DO}_{2}\right)$. Clinical symptoms vary widely and include pallor, nausea, vomiting, weakness, fatigue, irritability, tachycardia, tachypnea and edema. However, it is not clear what the impact of anemia itself is on outcome of critically ill children. $\mathrm{A} \mathrm{Hb}<5 \mathrm{~g} / \mathrm{dL}$ has been associated with increased mortality in non-critically ill children [4-6]. Furthermore, anemia was identified as an independent predictor for mortality in critically ill adults, whereas one group of investigators
Table 20.2 First-line diagnostic tests in anemia

\begin{tabular}{ll}
\hline & Test \\
\hline Screening & Complete blood count \\
& Red cell indices (MCV, MCHC) \\
& Peripheral blood film \\
& Reticulocyte count \\
\hline Confirmatory & Coombs test (direct and indirect) \\
& Hemoglobin electrophoresis \\
& G-6-PD assay \\
& Bone marrow aspirate \\
& Iron studies \\
& Serum B12 and folate \\
& Haptoglobin \\
\hline
\end{tabular}

$M C V$ mean corpuscular volume, $M C H C$ mean corpuscular hemoglobin concentration, $G-6-P D$ glucose-6-phosphate dehydrogenase deficiency

did not observe such an association in a heterogeneous group of critically ill children [7, 8]. Importantly, the landmark paper from the TRIPICU study has clearly shown that stable critically ill children can tolerate a $\mathrm{Hb}$ of $7 \mathrm{~g} / \mathrm{dL}$ without serious complications [9]. In this multicenter prospective study comprising 637 stable critically ill children the occurrence of new or progressive multiple organ dysfunction syndrome was similar between patients randomized to a restrictive transfusion strategy (threshold $\mathrm{Hb} 7 \mathrm{~g} / \mathrm{dL}$ ) and liberal transfusion strategy (threshold $\mathrm{Hb} 9.5 \mathrm{~g} / \mathrm{dL}$ ) within 7 days of PICU admission. A post-hoc analysis of postsurgical PICU patients and children after cardiac surgery showed similar findings $[10,11]$. At present, no data is available identifying a proper threshold for unstable critically ill children such as those with severe hypoxemia or hemodynamic compromise. Therefore, the decision to treat anemia is determined by the underlying cause, the acuteness, and the physiologic status of the child.

\section{Anemias of Underproduction and/or Impaired Maturation}

There are a number of diseases that lead to underproduction of erythrocytes and anemia, whereas iron deficiency or lead poisoning are well known causes of impaired maturation of RBCs. The majority of these conditions are chronic, with the exception of bone marrow failure affecting a single or even multiple cell lineages causing pancytopenia. The most common cause of acquired pancytopenia in the PICU is leukemia - either at presentation or as a consequence of chemotherapy or irradiation. Alternatively, many drugs often used in the PICU (e.g., antibiotics, ibuprofen, captopril and phenytoin) and infectious agents such as Parvovirus B19, hepatitis virus, Ebstein-Barr virus, cytomegalovirus, tuberculosis and human immunodeficiency virus are important causes of bone marrow failure. Of importance, pancytopenia 
Table 20.3 Diagnosis of anemia using cell indices

\begin{tabular}{llll}
\hline & Low MCV & Normal MCV & High MCV \\
\hline Normal RDW & Thalassemia trait & Lead toxicity & Aplastic anemia \\
& Iron deficiency & Liver disease & B12/folate deficiency \\
High RDW & Hemoglobin H disease & Immune hemolysis & \\
& & Sickle cell disease & \\
& & Heriditary spherocytosis & \\
\hline
\end{tabular}

$M C V$ mean corpuscular volume, $R D W$ red cell volume distribution width, $M C H C$ mean corpuscular hemoglobin concentration, $H D W$ hemoglobin distribution width

may present as sepsis with bruising, hemorrhage, pallor and fatigue. Symptoms develop usually gradually, but aplastic crisis can ultimately result in cardiovascular collapse. Peripheral blood smear will show normocytic anemia with a low or absent number of granulocytes and platelets. Although many cases are mild and self-limiting, supportive therapy such as eliminating identifiable causative toxins or treating underlying infections or malignancy is indicated. Transfusion is indicated when there is cardiovascular compromise, though as discussed in the previous chapter, there are no standard threshold criteria for transfusion that can be applied in every situation.

\section{Anemias of Increased Turnover or Destruction}

Many hematological diseases may result in severe hemolytic anemia, such as sickle cell disease (SCD), thalassemias and (non-) immune mediated hemolysis.

\section{Sickle Cell Disease}

Sickle cell disease (SCD) is one of the most important causes of hemolytic anemia that may bring a patient into the PICU. SCD is the general term for all phenotypes related to mutations in the hemoglobin gene found at chromosome $11 \mathrm{p} 15.4$ that are characterized by red cell sickling following hemoglobin deoxygenation, chronic hemolysis, recurrent vaso-occlusion, and ischemic injury to various organs [12]. Sickle cell anemia (SCA) is the most common form of SCD. It is an autosomal recessive disease caused by the substitution of valine for glutamine at the sixth amino acid position of the beta chain of the hemoglobin gene. Sickle cell trait (SCT) differs from SCA in that it is a heterozygous condition and does not cause active disease. SCA primarily affects individuals from African, Mediterranean, Indian, and Middle Eastern descent, although there is also a high incidence among Hispanic individuals from the Caribbean, Central American and some South American countries [13].

Factors that promote sickling include desaturation of hemoglobin (either by failure to oxygenate in the lungs,
Table 20.4 Factors that may promote sickling

\begin{tabular}{ll}
\hline Hemoglobin desaturation & $\begin{array}{l}\text { No oxygenation in the lungs } \\
\text { (atelectasis, pulmonary infection, } \\
\text { chronic lung disease, pulmonary } \\
\text { vascular disease, high altitude) } \\
\text { Diminished oxygen delivery (decreased } \\
\text { cardiac output, severe anemia) } \\
\text { Increased tissue extraction of oxygen } \\
\text { (exercise, thyrotoxicosis, (malignant) } \\
\text { hyperthermia, sepsis, seizures, } \\
\text { shivering, acidosis) }\end{array}$ \\
\hline Increased microvascular & $\begin{array}{l}\text { Increased viscosity of blood } \\
\text { (transfusion, dehydration) }\end{array}$ \\
transit time & Vasoconstriction (hypothermia, use of \\
& vasoconstrictor drugs)
\end{tabular}

diminished $\mathrm{DO}_{2}$ or increased tissue extraction of oxygen), and increased microvascular transit time as seen in dehydration or vasoconstriction (Table 20.4). The number of RBCs that sickle depends on the extent and duration of deoxygenation, the proportion of abnormal B-chain in the $\mathrm{Hb}(\mathrm{HbS})$ of affected cells, and the presence of fetal $\mathrm{Hb}$ in the erythrocytes. The conformational change in $\mathrm{HbS}$ enables polymerization between $\mathrm{Hb}$ molecules. Children with $\mathrm{SCD}$ may carry up to $90-100 \%$ of $\mathrm{HbS}$. HbF effectively reduces the concentration of $\mathrm{HbS}$ [14]. Hydroxyurea promotes the formation of $\mathrm{HbF}$, hence its use is recommended in all patients with SCD to prevent SCD related complications [15]. Next to this, increased endothelial activity with production of endothelin and circulation of soluble cell adhesion molecules promotes sickle cell adhesion [16, 17]. Activation of platelets, adhesion of neutrophils, and proinflammatory cytokine release further promote sickling.

Many life-threatening complications of SCD result from occlusion of the microcirculation. The first includes acute splenic sequestration crisis and transient aplastic crisis (TAC). TAC occurs in patients with SCD when there is a transient suppression of erythropoiesis following infection with a viral agent such as human parvovirus B19. This usually lasts for several days. Clinical symptoms rarely include hemodynamic instability; hence, clinical management is mainly supportive. 
Acute chest syndrome (ACS), cerebrovascular accidents (CVA) and vaso-occlusive crises (VOC) are other manifestations of occlusion of the microcirculation.

\section{Acute Splenic Sequestration}

Acute splenic sequestration crisis is characterized by a sudden pooling of blood in the splenic sinusoids resulting in severe anemia. It typically occurs in children between 10 and 27 months of age, though it can also occur in young infants. It is relatively uncommon in older children because they develop functional asplenia over time, caused by repeated infarctions and subsequent fibrosis of the spleen, or autosplenectomy. Acute splenic sequestration crisis often occurs during bacterial or viral infection. Symptoms can range from mild to severe and include splenomegaly and symptoms of intravascular volume depletion. Laboratory investigations show an acute drop in $\mathrm{Hb}(>2 \mathrm{~g} / \mathrm{dL})$, reticulocytosis, thrombocytopenia, and leucopenia. The mainstay of treatment is to restore circulating blood volume and hemodynamic stability through infusion of volume expanders, and by repeated blood or exchange transfusions. One group of investigators has reported substantial mortality (35\%) when the Hb level dropped $>4 \mathrm{~g} / \mathrm{dL}$. Performing a splenectomy after a first crisis is controversial because of the infectious risks associated with splenectomy. Alternatively, close long-term monitoring of the child may avoid the need for splenectomy.

\section{Acute Chest Syndrome}

ACS is one of the most common complications of SCD and is associated with significant morbidity and mortality (mortality rates ranging from 1.8 to $5 \%$ ) [18]. Pulmonary microvascular sequestration of sickled RBCs initiates ACS, leading to acute lung injury (ALI) or even ARDS necessitating mechanical ventilation [19]. Clinical symptoms include fever, (productive) cough, chest pain, dyspnea, hemoptysis, and hypoxia. Of note, these symptoms may not be present initially but frequently develop during disease course in response to other precipitating events. Laboratory investigations show leukocytosis and presence of mainly isolated upper or middle lobe consolidations on chest radiograph. Pleural effusions are less common, in contrast with adults. Repetitive episodes of ACS may have significant long-term consequences such as pulmonary fibrosis, pulmonary hypertension, or cor pulmonale. Pulmonary hypertension in ACS is associated with increased mortality in adults, but this does not seem to be the case for children and adolescents [20].

The exact pathophysiological mechanisms of ACS remains to be elucidated, but precipitating factors include bacterial and viral infections (especially in young children in winter months), higher steady-state Hb level, increased neutrophil count, and atelectasis (Table 20.5) [22]. Patients at risk for ACS may be identified by serum secretory phospholipase A2 levels [23], though this test is not widely available.
Table 20.5 Possible indications for red blood cell transfusion in sickle cell disease

\begin{tabular}{ll}
\hline Prophylactic & Pre-operative \\
& Post-stroke \\
& Abnormal transcranial Doppler flow rates \\
\hline Therapeutic & Acute chest syndrome \\
& Transient ischemic attack \\
& Stroke \\
& Spinal cord infarct \\
& Persistent priapism \\
& Aplastic crisis \\
& Splenic sequestration crisis \\
& Refractory vaso-occlusive crisis
\end{tabular}

Based on data from Ref. [21]

Many patients with SCD also suffer from hyperreactive airways or asthma [24].

Treatment of ACS centers on treating the underlying pulmonary infection (if presumed present) and preventing infarction of lung tissue. Treating the infection prevents hypoxia and acidosis, two important risk factors of sickling; prevention of infarction minimizes pain and hypoventilation (which in itself is a risk for pulmonary infection). Therefore, conventional treatment includes oxygen, intravenous fluid hydration, broad-spectrum antibiotics, pain medications and transfusion therapy. Transfusion alone often results in significant clinical improvement [22]. Exchange transfusion aimed at decreasing $\mathrm{HbS}<30 \%$ is indicated when the patient is severely hypoxemic or has widespread pulmonary infarction. Bronchoconstriction needs to be treated, if present. Adjunctive therapeutic interventions have emerged including corticosteroids and nitric oxide (NO). Dexamethasone limited the severity in one small study of 43 patients, but was also associated with increased rehospitalization after $72 \mathrm{~h}$ [25]. The use of NO in critically ill children with ACS has so far only been described in case reports; hence its routine use cannot be recommended.

\section{Cerebrovascular Accidents}

CVAs are the other predominant leading cause of morbidity and mortality in children with homozygous SCD admitted to the PICU [26]. By the age of 20 years, approximately $11 \%$ of all patients will have suffered from infarcts, most frequently resulting from stenosis of large cerebral arteries (mainly the distal internal carotid artery and the proximal middle cerebral artery) [27]. Strikingly, approximately $15-25 \%$ of patients with SCD have silent cerebral infarction [28]. Recent or recurrent ACS is a significant risk factor for the later development of stroke, which suggests that repeated damage to the endothelium may contribute. Abnormal cerebral flow on transcranial Doppler (TCD) ultrasound seems to be another risk factor in children [29]. Older children and adolescent suffer more often from hemorrhagic stroke caused 
by ruptured aneurysms. Importantly, chronic transfusion therapy in children with SCA significantly decreased the occurrence of CVAs [30, 31]. The diagnosis of CVAs in patients with SCA is not different from other patients with CVA. Emergency management includes adequate oxygenation and exchange transfusion (targeted towards $\mathrm{HbS}$ $<20 \%$ ) [32].

\section{Vaso-Occlusive Crisis}

VOC is a challenging and perhaps the most common complication of SCD. It is characterized by a vicious circle of sickling, micro-vascular occlusion and hypoxemia. It can occur in almost any organ in the body causing organ-specific symptoms, fever, leukocytosis and pain. The pain can be very severe. Bones are predominantly affected. Abdominal crises are difficult to discriminate from other acute or surgical abdominal diseases. Emergency management of VOC consists of adequate hydration, oxygenation, and pain control with analgesic and anti-inflammatory drugs (i.e. opioids and non-steroidal anti-inflammatory drugs). RBC transfusion may be indicated to break the vicious circle of sickling.

\section{Functional Asplenia}

Functional asplenia is common in SCD. Patient with SCD are therefore susceptible to sepsis caused by encapsulated bacteria such as Streptococcus pneumoniae and Haemophilus influenzae. Sepsis is a major cause of death in children with SCD. Preventive measures such as immunization against encapsulated bacteria and prophylactic antibiotic usage have significantly improved patient outcome [33]. Nonetheless, empiric broad-spectrum antibiotic therapy is indicated in children with SCD children when an infection is suspected.

\section{Transfusion Therapy in Patients with SCD}

The primary goal of transfusion therapy is to restore the appropriate $\mathrm{Hb}$ and hemotocrit $(\mathrm{Ht})$ level. However, children with SCD are chronically anemic; hence, compensatory mechanisms have set in to ensure maintenance of adequate $\mathrm{DO}_{2}$. In addition, higher Ht levels increase blood viscosity, enhancing the risk of sickling in the microcirculation. Thus, in general RBC transfusion should be used as little as possible in children with SCD except for specific indications (Table 20.6). However, exchange transfusions may be more indicated in critically ill children in order to minimize the risk of microvascular sickling; the primary goal would be to achieve an $\mathrm{HbS}<30 \%$. Children undergoing surgery under general anesthesia are at increased risk for severe complications such as acute chest syndrome, painful crises, neurologic complications (stroke, seizures) or renal failure.

\section{Schistocytosis}

Schistocytes are fragments of RBCs formed by exposure to turbulence, shear stress, pressure fluctuation and collision
Table 20.6 Commonly used drugs that need to be avoided in glucose6-phoshate dehydrogenase deficiency

\begin{tabular}{ll}
\hline Antibiotics & Chloramphenicol \\
& Ciprofloxacin \\
& Sulfamethoxazole \\
& Nalidix acid \\
\hline Antimalarials & Chloroquine \\
& Primaquine \\
\hline Miscellaneous & Methylene blue \\
& Doxorubicin \\
& Vitamin K analogs \\
& Fava beans \\
& Moth balls \\
\hline
\end{tabular}

with surfaces (schistocytosis). This form of hemolysis is caused by micro-angiopathic hemolysis (i.e. at the level of the arterioles), macro-angiopathic hemolysis (for instance in hemangiomas), and mechanical hemolysis in patients on extra-corporeal life support (ECLS). The most frequent causes of micro-angiopathic hemolysis in children presenting to the PICU include disseminated intravascular coagulation (DIC), hemolytic-uremic syndrome (HUS) and subacute bacterial endocarditis.

A triad consisting of hemolysis, thrombocytopenia, and acute renal failure (ARF) defines HUS. It is part of a spectrum that includes thrombocytopenic thrombotic purpura, which is seen more often in adults and is characterized by a more important neurologic involvement. Numerous - mainly infectious - agents trigger HUS; Escherichia coli $\mathrm{O} 157: \mathrm{H7}$ is the most common, and it is frequently related to insufficient heating of meat. The pathophysiology of HUS is not clear, but likely involves injury to the endothelial cells involving ADAMTS-13 (a von Willebrand factor cleavage protein) and factor $\mathrm{H}$ (a complement $\mathrm{C} 3$ convertase inhibitor) [34]. This causes microthrombi and fibrin strands in arterioles that damage RBCs and cause platelet aggregation leading to anemia and thrombocytopenia. Children with HUS frequently present with acute renal failure. Other features include bowel involvement mimicking acute abdomen and central nervous involvement including seizures or altered consciousness. Therapy is mainly supportive and may require renal replacement therapy. Plasma exchange therapy may be beneficial [35] and is reviewed elsewhere in this textbook. Platelet transfusion is rarely indicated.

Macro-angiopathic hemolysis may be observed in patients in whom prosthetic heart valves have been implanted. Critical care intervention is only required in children with macro-angiopathic hemolysis when complications of the Kasabach-Merritt syndrome develop. Mechanical schistocytic hemolysis in patients on ECLS occurs when the blood flow is set above limits, small cannulas are used, large negative pressures are generated, and blood is exposed to foreign surfaces. Monitoring free $\mathrm{Hb}$ is used for evaluating the extent 
of hemolysis in children on ECLS. It is also postulated that free $\mathrm{Hb}$ has clinical consequences such as renal impairment, but this has yet to be elucidated [36].

\section{Red Cell Membrane Defects}

Congenital and acquired intrinsic red cell membrane defects rarely require admission to the PICU, but may be observed in patients admitted to the PICU for other reasons. Acquired membrane red cell defects are caused by burns (either direct or indirect via oxygen radicals), toxins from streptococcal or staphylococcal infection, infection, drugs (such as antibiotics) or transfusion with plasma products [37-39]. Children with paroxysmal nocturnal hemoglobinuria $(\mathrm{PNH})$ may present with venous thrombo-embolism in unusual locations and a history of recurrent sinopulmonary infection or septicemia. Thrombotic events, which can be lethal, are refractory to thrombolytic therapy [40]. Hereditary spherocytosis is a congenital red cell membrane defect that can be associated with life-threatening crises after parvovirus B19 infection, when there is an imbalance between inadequate production due to acquired bone marrow failure and hemolysis.

\section{Red Cell Metabolism Defects}

It is rare that patients with red cell metabolism defects need critical care, apart from patients with glucose-6-phospate deficiency (G6PD). G6PD is an X-linked inherited disease with high prevalence rates in tropical Africa, Middle East, tropical and subtropical Asia, and some areas of the Mediterranean Sea [41]. Patients become symptomatic when the enzyme activity is less than $60 \%$. Glucose-6-phosphate dehydrogenase handles oxidative stress in the erythrocyte. It catalyzes the reduction of nicotinamide adenine dinucleotide phosphate (NADP) to NADPH in the hexose-monophosphate shunt, which in turn converts glutathione disulfide to reduced gluthathione. Gluthathione is a scavenger for oxygen radicals. Patients with G6PD deficiency may present with severe acute hemolytic anemia caused by stressors such as drugs (Table 20.7), infection or notably ingestion of fava beans. Treatment consists mainly of eliminating (if possible) the precipitating agent; RBC transfusions may be indicated.

\section{Immune-Mediated Hemolysis}

Immune-mediated hemolysis is discriminated into alloimmune and autoimmune. Alloimune hemolysis occurs when the child passively acquires RBC antibodies during transfusion with RBC preparations containing donor antibodies. Autoimmune hemolytic anemia (AHIA) occurs when a child intrinsically develops antibodies against $\mathrm{RBCs}$ with (primary AIHA) or without (secondary AIHA) accompanying systemic illness.

Primary AIHA usually occurs after a viral infection. The child suffers from symptoms of anemia and dark urine. Because of the rapid onset, other symptoms such as jaundice
Table 20.7 Causes of secondary autoimmune hemolytic anemia

\begin{tabular}{ll}
\hline Immune mediated & Evans syndrome \\
& Rheumatoid arthritis \\
& Systemic lupus erythematosus \\
& Evans syndrome \\
\hline Infectious & Clostridium difficile \\
& Epstein-Barr virus \\
& Measles \\
& Mycoplasma pneumoniae \\
& Paramyxovirus \\
& Rubella \\
& Varicella zoster \\
& Congenital \\
& Acquired (human immunodeficiency virus) \\
Immunodeficiency & Hodgkin's lymphoma \\
& Leukemia \\
Malignancy & Myelodysplasia \\
& Acetaminophen \\
& Cephalosporins \\
Drugs & Ibuprofen \\
& Penicillins \\
\end{tabular}

Table 20.8 Differential diagnosis of secondary erythrocytosis

\begin{tabular}{ll}
\hline Hypoxia & Cyanotic congenital heart disease \\
& Obstructive sleep apnea \\
& Smoking and chronic carbon monoxide exposure \\
& High altitude \\
& High affinity hemoglobin \\
\hline Renal & Renal artery stenosis \\
& Cysts \\
& Post-transplant \\
& Focal glomerulonephritis \\
& Twin-to-twin transfusion \\
& Placental insufficiency \\
& Maternal diabetes \\
& Beckwith-Wiedemann syndrome \\
& Erythropoeitin secreting tumors \\
& Growth hormone excess \\
\hline
\end{tabular}

or reticulocytosis may not be present. Laboratory studies show isolated anemia, low haptoglobin, spherocytes on peripheral blood smear and a positive direct antiglobulin (i.e. Coombs) test. The indirect Coombs test detects antibodies in the patients' serum. Supportive therapy includes plasma exchange. Transfusion should be avoided unless severe anemia with cardiovascular compromise occurs. Further therapy (e.g., high-dose corticosteroids) is dependent upon the type of primary AIHA, which is defined by the presence of IgG antibodies (suggesting warm-reactive AIHA) or complement (suggesting cold-reactive AIHA). Cold-reactive AIHA is then classified by which type of antibody (IgM auto-antibody or IgG) is detected. Secondary AIHA occurs in a wide variety of disease (Table 20.8). 


\section{Thalassemias}

Thalassemias are a group of inherited disorders of hemoglobin synthesis. Although they are more common than SCD, patients with thalassemias are not often primarily seen in the PICU. Patients with the transfusion-dependent form of thalassemia (thalassemia major) may experience complications from iron overload sepsis. The risk of sepsis is increased because many patients underwent splenectomy or have indwelling vascular devices implanted for repetitive transfusion or chelation therapy [42]. Improved chelation therapy regimens have decreased the complication rate of myocardial iron overload necessitating inotropic support that was often required in adolescents with thalassemia major [42].

\section{Secondary Hemoglobinopathies}

Secondary hemoglobinopathies, or dyshemoglobinemias, include methemoglobinemia (MetHb) in patients treated with nitric oxide (NO), carboxyhemoglobinemia $(\mathrm{COHb})$ in patients intoxicated with carbon monoxide $(\mathrm{CO})$, or other toxins. $\mathrm{Hb}$ binds to $\mathrm{CO} 210$ times more easily than $\mathrm{O}_{2}$. This means that $\mathrm{COHb}$ cumulates until typical symptoms occur (threshold in adults is about $20 \%$ but in children this may be lower). $\mathrm{COHb}$ cannot bind to $\mathrm{O}_{2}$, and the oxygen dissociation curve shifts leftwards further contributing to anoxia. The vasodilatory drug nitroprusside is notorious because it contains five cyanide molecules and one molecule of NO bound to iron. Critically ill children and those with rapid infusion of nitroprusside cannot eliminate the cyanide quickly enough to prevent toxic effects.

Dyshemoglobinemias result in shifting of the oxygen dissociation curve, impairment of binding of $\mathrm{O}_{2}$ by $\mathrm{Hb}$ and impairment of $\mathrm{O}_{2}$ delivery. MetHb usually becomes symptomatic when concentrations approximate $35-50 \%$. Treatment consists of removing the toxin and providing antidote if applicable (i.e. ascorbic acid or methylene blue for $\mathrm{MetHb}$ or pure $\mathrm{O}_{2}$ for $\mathrm{CO}$ intoxication). Exchange transfusion or hyperbaric oxygen therapy is indicated for lifethreatening causes with clinically impaired $\mathrm{DO}_{2}$.

\section{Hemophagocytosis}

Hemophagocytic lymphohistiocytosis (HLH) syndrome is a devastating multisystem disease with a poor prognosis [43]. The initiating event of reactive HLH is unknown, but it has been associated with infectious agents such as EBV or autoimmune disorders. Congenital HLH is a malignancy. Twenty percent of HLH is familial and associated with abnormalities of a natural killer cell-derived cytotoxin (perforin). HLH is characterized by aggressive destruction of RBCs and other blood elements by macrophages in bone marrow, liver and spleen. Clinical symptoms vary and are similar to the systemic inflammatory response syndrome (SIRS). The disease can be recognized if the patient meets at least five of the following criteria: (a) fever, (b) splenomegaly, (c) cytopenias of two or more lineages, (d) hypertriglyceridemia $(>3.0 \mathrm{mmol} / \mathrm{L})$ and/or hyperfibrinogenemia $(\leq 1.5 \mathrm{~g} / \mathrm{L})$, (e) hemophagocytosis seen in bone marrow (no malignancy seen), spleen or lymph node, (f) low or absent natural killer cell activity, (g) ferritin $\geq 500 \mathrm{mcg} / \mathrm{L}$ ), and (h) soluble CD25 $\geq 2,400 \mathrm{U} / \mathrm{mL}$ ) [44]. Other supportive findings include CSF pleiocytosis, elevated serum transaminases, elevated bilirubin, and elevated LDH. Treatment in the PICU is supportive. The only curative option for congenital HLH is bone marrow transplantation.

\section{Erythrocytosis}

An increase in circulating RBCs is termed erythrocytosis. It very rarely primarily leads to critical care intervention, but may be seen in patients admitted for any other reason. Secondary erythrocytosis originates from hypoxia such as in patients with right-to-left shunting cardiac lesion or pulmonary disease and patients living in high altitude, whereas spurious erythrocytosis is caused by dehydration, hemoconcentration or polyuria. Patients with primary erythrocytosis have normal levels of erythropoietin, but it is increased in those with secondary erythrocytosis. Arterial hematocrit $>65 \%$ may aggravate tissue hypoxia, cause thrombosis and necessitate the use of reduction exchange transfusions. The volume of blood that needs to be exchanged is calculated by multiplying the child's estimated blood volume by the desired reduction in hematocrit. In the infant, the removal rate should not exceed $2 \mathrm{~mL} / \mathrm{kg} / \mathrm{min}$.

\section{Part 2: Non-malignant White Blood Cell Disorders}

The type of leukocytosis is defined by specifying the WBC type along with the underlying cause of the increase. Stress mobilizes neutrophils from the bone marrow into the circulation or shifts marginated neutrophils. These are circulating neutrophils that were not active but can be mobilized in times of stress. True neutrophilia results from infection (both bacterial and viral), the band form is considered to be very suggestive for bacterial infection and thus routinely used in daily critical care [45]. In severe infections, neutropenia may occur because of insufficient formation of new neutrophils. Leukemoid reactions (i.e. neutrophils $>50,000$ cells/microL) can be triggered by various diseases but can only be discriminated from true leukemia through laboratory studies including marrow histology. Of particular concern are children with trisomy 21 who initially may have 
leukemoid reactions that develop into myeloid leukemias. Lymphocytosis is classically known to occur in Bordetella pertussis infection and following viral infection, whereas lymphopenia is often transient resulting from viral, fungal or parasitic infections. Yet, one should be aware of chronic underlying diseases including HIV infection. Eosinophilia is associated with allergic conditions or parasitic infections. Monocytosis is commonly caused by infections (tuberculosis, subacute bacterial endocarditis, syphilis, brucellosis, infectious mononucleosis, malaria) or autoimmune disorders (such as systemic lupus erythematosus and sarcoidosis).

\section{Part 3: Platelet Disorders}

\section{Thrombocytopenia}

Thrombocytopenia in critically ill children is relatively common and results from underproduction, overconsumption, or both (as for instance during sepsis). In addition, it is not uncommon to observe thrombocytopenia caused by inadequate sampling or technical impairments in the laboratory. In general, the underlying cause is usually determined easily. If not, then additional investigations including thrombopoietin levels need to be measured [46]. The clinical spectrum of thrombocytopenia ranges from bruising, petechia and epistaxis to significant, life threatening bleeding. Hence, the decision when to transfuse platelets depends on the risk of bleeding and underlying disease.

\section{Increased Consumption of Platelets}

There are many causes of thrombocytopenia caused by increased consumption of platelets, of which DIC and HUS are the most predominant. Hemorrhage and cardiopulmonary bypass-related thrombocytopenia are also common. Burns causes sequestration of platelets in proportion to the area injured - persistence of thrombocytopenia in these patients may indicate DIC or sepsis. Meningococcemia is notorious for causing purpura fulminans, but this may occur also when infected with other agents. In patients with meningococcemia, the initial and serial assessment of platelet and neutrophil count may be used as a prognostic score $[47,48]$. Likewise, platelet count is also predictive for the need of renal support in patients with Rocky Mountain spotted fever. Foreign surfaces in ECLS systems used in cardiac surgery activate and absorb platelets. This can be prevented by optimizing anticoagulant therapy and heparin coating of circuit components, timely changes of the circuit and post membrane platelet transfusion.
Additional measures suggested include the use of aprotonin in young children [49].

\section{Increased Destruction of Platelets}

Idiopathic thrombocytopenic purpura (ITP) is caused by splenic phagocytosis of antibody-coated platelets [50]. The acute form is self-limiting; it cures spontaneously within several weeks following the precipitating viral infection. Approximately $20 \%$ of affected children develop chronic ITP (i.e. $<150,000$ cells $/ \mathrm{mcL}$ ). The mortality in ITP is very low (i.e. $1 \%$ ) and mainly caused by intracranial hemorrhage. Diagnosis and treatment is in adherence with guidelines from the American Society of Hematology [51]. Heparininduced thrombocytopenia is relatively uncommon in critically ill children. It is caused by the formation of autoantibodies against heparin-platelet protein four complexes. In addition, the IgG antibodies activate platelets resulting in a prothrombotic state.

\section{Decreased Production of Platelets}

Reduced platelet synthesis rarely constitutes an acute problem.

\section{Thrombocytosis}

Thrombocytosis is defined as a platelet count $>450,000$ cells/ mcL. Primary thrombocytosis is very uncommon in children, but secondary thrombocytosis has various causes including Kawasaki disease. The major complication of thrombocytosis is thrombosis, but it is unknown at what threshold to start preventive measures. In patients with Kawasaki, aspirin is initiated to prevent coronary thrombus formation.

\section{References}

1. Bateman ST, Lacroix J, Boven K, Forbes P, Barton R, Thomas NJ, et al. Anemia, blood loss, and blood transfusions in North American children in the intensive care unit. Am J Respir Crit Care Med. 2008;178:26-33.

2. Kneyber MC. Red blood cell transfusion in paediatric critical care. Clin Lab. 2011;57:263-6.

3. Sadowitz PD, Amanullah S, Souid AK. Hematologic emergencies in the pediatric emergency room. Emerg Med Clin North Am. 2002;20:177-98, vii.

4. English M, Ahmed M, Ngando C, Berkley J, Ross A. Blood transfusion for severe anaemia in children in a Kenyan hospital. Lancet. 2002;359:494-5.

5. Lackritz EM, Campbell CC, Ruebush TK, Hightower AW, Wakube W, Steketee RW, et al. Effect of blood transfusion on survival among children in a Kenyan hospital. Lancet. 1992;340:524-8.

6. Lackritz EM, Hightower AW, Zucker JR, Ruebush TK, Onudi CO, Steketee RW, et al. Longitudinal evaluation of severely anemic 
children in Kenya: the effect of transfusion on mortality and hematologic recovery. AIDS. 1997;11:1487-94.

7. Corwin HL, Gettinger A, Pearl RG, Fink MP, Levy MM, Abraham E, et al. The CRIT study: anemia and blood transfusion in the critically ill-current clinical practice in the United States. Crit Care Med. 2004;32:39-52.

8. Kneyber MC, Hersi MI, Twisk JW, Markhorst DG, Plotz FB. Red blood cell transfusion in critically ill children is independently associated with increased mortality. Intensive Care Med. 2007;33: 1414-22.

9. Lacroix J, Hebert PC, Hutchison JS, Hume HA, Tucci M, Ducruet $\mathrm{T}$, et al. Transfusion strategies for patients in pediatric intensive care units. N Engl J Med. 2007;356:1609-19.

10. Rouette J, Trottier H, Ducruet T, Beaunoyer M, Lacroix J, Tucci M. Red blood cell transfusion threshold in postsurgical pediatric intensive care patients: a randomized clinical trial. Ann Surg. 2010;251: 421-7.

11. Willems A, Harrington K, Lacroix J, Biarent D, Joffe AR, Wensley $\mathrm{D}$, et al. Comparison of two red-cell transfusion strategies after pediatric cardiac surgery: a subgroup analysis. Crit Care Med. 2010;38:649-56.

12. Rogers KL, Fey PD, Rupp ME. Coagulase-negative staphylococcal infections. Infect Dis Clin North Am. 2009;23:73-98.

13. Modell B, Darlison M. Global epidemiology of haemoglobin disorders and derived service indicators. Bull World Health Organ. 2008;86:480-7.

14. Bunn HF. Pathogenesis and treatment of sickle cell disease. N Engl J Med. 1997;337:762-9.

15. McGann PT, Ware RE. Hydroxyurea for sickle cell anemia: what have we learned and what questions still remain? Curr Opin Hematol. 2011;18:158-65.

16. Graido-Gonzalez E, Doherty JC, Bergreen EW, Organ G, Telfer M, McMillen MA. Plasma endothelin-1, cytokine, and prostaglandin E2 levels in sickle cell disease and acute vaso-occlusive sickle crisis. Blood. 1998;92:2551-5.

17. Liem RI, O'Gorman MR, Brown DL. Effect of red cell exchange transfusion on plasma levels of inflammatory mediators in sickle cell patients with acute chest syndrome. Am J Hematol. 2004;76: 19-25.

18. Platt OS, Brambilla DJ, Rosse WF, Milner PF, Castro O, Steinberg $\mathrm{MH}$, et al. Mortality in sickle cell disease. Life expectancy and risk factors for early death. N Engl J Med. 1994;330:1639-44.

19. Vichinsky EP, Neumayr LD, Earles AN, Williams R, Lennette ET, Dean D, et al. Causes and outcomes of the acute chest syndrome in sickle cell disease. National acute chest syndrome study group. $\mathrm{N}$ Engl J Med. 2000;342:1855-65.

20. Zuckerman WA, Rosenzweig EB. Pulmonary hypertension in children with sickle cell disease. Expert Rev Respir Med. 2011;5: 233-43.

21. Sullivan KJ, Kisson N, Goodwin RS. Sickle cell disease. In: Nicols DG, editor. Roger's textbook of pediatric intensive care. 4th ed. Philadelphia: Wolter Kluwers Health; 2008. p. 1799-812.

22. Miller ST. How I, treat acute chest syndrome in children with sickle cell disease. Blood. 2011;117:5297-305.

23. Styles LA, Abboud M, Larkin S, Lo M, Kuypers FA. Transfusion prevents acute chest syndrome predicted by elevated secretory phospholipase A2. Br J Haematol. 2007;136:343-4.

24. Morris CR. Asthma management: reinventing the wheel in sickle cell disease. Am J Hematol. 2009;84:234-41.

25. Bernini JC, Rogers ZR, Sandler ES, Reisch JS, Quinn CT, Buchanan GR. Beneficial effect of intravenous dexamethasone in children with mild to moderately severe acute chest syndrome complicating sickle cell disease. Blood. 1998;92:3082-9.
26. Bartram JL, Thein SL, Gardner K, Egberongbe Y, D'Silva P, Height $\mathrm{SE}$, et al. Outcome of children with sickle cell disease admitted to intensive care - a single institution experience. Br J Haematol. 2010;150:614-7.

27. Ohene-Frempong K, Weiner SJ, Sleeper LA, Miller ST, Embury S, Moohr JW, et al. Cerebrovascular accidents in sickle cell disease: rates and risk factors. Blood. 1998;91:288-94.

28. Miller ST, Macklin EA, Pegelow CH, Kinney TR, Sleeper LA, Bello JA, et al. Silent infarction as a risk factor for overt stroke in children with sickle cell anemia: a report from the cooperative study of sickle cell disease. J Pediatr. 2001;139:385-90.

29. Adams RJ, McKie VC, Carl EM, Nichols FT, Perry R, Brock K, et al. Long-term stroke risk in children with sickle cell disease screened with transcranial Doppler. Ann Neurol. 1997;42:699-704.

30. Adams RJ, McKie VC, Hsu L, Files B, Vichinsky E, Pegelow C, et al. Prevention of a first stroke by transfusions in children with sickle cell anemia and abnormal results on transcranial Doppler ultrasonography. N Engl J Med. 1998;339:5-11.

31. Adams RJ, Brambilla D. Discontinuing prophylactic transfusions used to prevent stroke in sickle cell disease. N Engl J Med. 2005;353:2769-78.

32. Islam MS, Anoop P. Current concepts in the management of stroke in children with sickle cell disease. Childs Nerv Syst. 2011;27: 1037-43.

33. Davies EG, Riddington C, Lottenberg R, Dower N. Pneumococcal vaccines for sickle cell disease. Cochrane Database Syst Rev. 2004;1:CD003885.

34. Kavanagh D, Goodship T. Genetics and complement in atypical HUS. Pediatr Nephrol. 2010;25:2431-42.

35. Bambauer R, Latza R, Schiel R. Therapeutic apheresis in the treatment of hemolytic uremic syndrome in view of pathophysiological aspects. Ther Apher Dial. 2011;15:10-9.

36. Zager RA, Gamelin LM. Pathogenetic mechanisms in experimental hemoglobinuric acute renal failure. Am J Physiol. 1989;256: F446-55.

37. Armutcu F, Gurel A, Hosnuter M, Pabuccu O, Altnyazar C. Caffeic acid phenethyl ester improves oxidative erythrocyte damage in a rat model of thermal injury. J Burn Care Rehabil. 2004;25:171-8.

38. Menestrina G, Serra MD, Prevost G. Mode of action of beta-barrel pore-forming toxins of the staphylococcal alpha-hemolysin family. Toxicon. 2001;39:1661-72.

39. Nizet V. Streptococcal beta-hemolysins: genetics and role in disease pathogenesis. Trends Microbiol. 2002;10:575-80.

40. Socie G, Mary JY, de Gramont A, Rio B, Leporrier M, Rose C, et al. Paroxysmal nocturnal haemoglobinuria: long-term follow-up and prognostic factors. French society of haematology. Lancet. 1996:348:573-7.

41. Cappellini MD, Fiorelli G. Glucose-6-phosphate dehydrogenase deficiency. Lancet. 2008;371:64-74.

42. Cunningham MJ, Macklin EA, Neufeld EJ, Cohen AR. Complications of beta-thalassemia major in North America. Blood. 2004;104:34-9.

43. Janka GE. Familial and acquired hemophagocytic lymphohistiocytosis. Annu Rev Med. 2012;63:233-46.

44. Risma K, Jordan MB. Hemophagocytic lymphohistiocytosis: updates and evolving concepts. Curr Opin Pediatr. 2012;24:9-15.

45. Hsiao AL, Baker MD. Fever in the new millennium: a review of recent studies of markers of serious bacterial infection in febrile children. Curr Opin Pediatr. 2005;17:56-61.

46. Emmons RV, Reid DM, Cohen RL, Meng G, Young NS, Dunbar $\mathrm{CE}$, et al. Human thrombopoietin levels are high when thrombocytopenia is due to megakaryocyte deficiency and low when due to increased platelet destruction. Blood. 1996;87:4068-71. 
47. Peters MJ, Ross-Russell RI, White D, Kerr SJ, Eaton FE, Keengwe IN, et al. Early severe neutropenia and thrombocytopenia identifies the highest risk cases of severe meningococcal disease. Pediatr Crit Care Med. 2001;2:225-31.

48. van Deuren M, Neeleman C, Van 't Hek LG, van der Meer JW. A normal platelet count at admission in acute meningococcal disease does not exclude a fulminant course. Intensive Care Med. 1998;24:157-61.

49. McDonough J, Gruenwald C. The use of aprotinin in pediatric patients: a review. J Extra Corpor Technol. 2003;35:346-9.
50. Blanchette V, Bolton-Maggs P. Childhood immune thrombocytopenic purpura: diagnosis and management. Hematol Oncol Clin North Am. 2010;24:249-73.

51. Bolton-Maggs P, Tarantino MD, Buchanan GR, Bussel JB, George $\mathrm{JN}$. The child with immune thrombocytopenic purpura: is pharmacotherapy or watchful waiting the best initial management? A panel discussion from the 2002 meeting of the American society of pediatric hematology/oncology. J Pediatr Hematol Oncol. 2004;26: 146-51. 